\title{
Perancangan Sistem Informasi Penerimaan Jasa Servis Pada CV. Java Multimedia Yogyakarta
}

\author{
Nani Purwati ${ }^{1}$, Novi Anggreani ${ }^{2}$ \\ ${ }^{1}$ Prodi Sistem Informasi Akuntnsi, Universitas Bina Sarana Informatika \\ ${ }^{2}$ Prodi Sistem Informasi, Universitas Bina Sarana Informatika \\ Nani.npi@bsi.ac.id, anggreaninovi1998@gmail.com
}

\begin{abstract}
CV. Java Multimedia is one of the laptop service provider companies which is certainly always trying to provide maximum service in order to increase customer loyalty. Based on interviews with company managers CV. Java Multimedia Yogyakarta, there are several problems in business processes, namely the absence of a service number that makes it difficult for customers and also employees, causing the exchange of goods in the process of taking. To support companies in carrying out business processes optimally to customers, the authors make "Design of Service Information Acceptance Information Systems at CV. Java Multimedia Yogyakarta ". Research methods used in data collection are the observation method, the interview method and the literature study method. This design uses software development techniques namely the Rapid Application Development (RAD) method which includes business modeling, data modeling, process modeling, application generation and testing. The author tests the website using Black Box Testing so that the system runs in accordance with the desired environment.
\end{abstract}

Keywords: Rapid Aplication Development,RAD, black box testing

Abstrak: CV. Java Multimedia merupakan salah satu perusahaan penyedia jasa servis laptop yang tentunya selalu berusaha untuk memberikan pelayanan yang maksimal demi meningkatkan loyalitas pelanggan. Berdasarkan wawancara dengan Manager perusahaan CV. Java Multimedia Yogyakarta terdapat beberapa permasalahan dalam proses bisnis, yaitu tidak adanya nomer servis yang menyulitkan pelanggan dan juga karyawan, menyebabkan tertukarnya barang dalam proses pengambilan. Untuk mendukung perusahaan dalam menjalankan proses bisnis secara optimal kepada pelanggan, penulis membuat "Perancangan Sistem Informasi Penerimaan Jasa Servis Pada CV. Java Multimedia Yogyakarta". Metode Penelitian yang digunakan dalam pengumpulan data adalah metode observasi, metode wawancara dan metode studi pustaka. Perancangan ini menggunakan teknik pengembangan software yaitu dengan metode Rapid Aplication Development (RAD) yang meliputi pemodelan bisnis, pemodelan data, proses pemodelan, generasi aplikasi dan pengujian. Penulis melakukan pengujian website menggunakan Black Box Testing agar sistem berjalan sesuai dengan lingkungan yang diinginkan.

Kata kunci: Rapid Aplication Development,RAD, black box testing (i) (2) $\begin{aligned} & \text { This is an open access article distributed under the Creative Commons Attribution License, which permits } \\ & \text { unrestricted use, distribution, and reproduction in any medium, provided the original work is properly cited. @2019 }\end{aligned}$ by author and IJSE-Indonesian Journal on Software Engineering.

\section{A. PENDAHULUAN}

Penggunaan gedget saat ini untuk menggantikan perangkat sejenis laptop semakin tinggi. Meskipun begitu, komputer dan laptop masih menjadi sebuah kebutuhan tersendiri bagi sebagian orang, terutama para pelajar, mahasiswa, guru, dosen ataupun pegawai. Ada kelebihan tersendiri bagi pemakai komputer atau laptop terhadap penggunaan komputer atau laptop yang tidak bisa begitu mudah digantikan dengan perangkat sejenis gadget. Laptop atau komputer jinjing, atau notebook, merupakan sebuah mobile komputer yang berukuran relatif kecil dan ringan (Hasanah, Ridarmin, Adrianto, 2017).

Sebagian besar dari para pengguna dihadapkan dengan masalah kerusakan pada laptop atau komputernya. Laptop atau komputer tidak selamanya akan berfungsi dengan baik, oleh karena itu membawa laptop atau komputer ke tempat penyedia jasa servis adalah salah satu pilihan bagi para pengguna yang memang tidak memiliki pengetahuan atau ketrampilan untuk 
memperbaikinya sendiri. Jasa dapat diartikan produk yang tidak berwujud yang biasanya berupa pelayanan yang dibutuhkan oleh konsumen. Sedangkan servis sering juga disebut dengan istilah perbaikan (Damayanti, Ambarita, 2018). Dijadikanya komputer atau laptop sebagai kebutuhan primer bagi sebagian besar masyarakat, salah satunya para pelajar atau mahasiswa. Menjadikan jasa servis laptop atau komputer sebagai salah satu peluang bisnis yang menjanjikan. Karenanya banyak perseorangan yang menjadi wirausaha dengan mendirikan perusahaan jasa servis laptop, salah satunya CV. Java Multimedia.

CV. Java Multimedia merupakan salah satu perusahaan penyedia jasa servis laptop yang tentunya mengutamakan kepuasan pelanggan, sayangnya pelayanan yang berjalan saat ini masih terdapat masalah, seperti, tidak adanya nomer servis yang menyulitkan perusahaan dan juga customer, menyebabkan terjadinya kesalahan atau tertukarnya barang pada saat pengambilan. Tidak menggunakan satu data yang terintegrasi atau terhubung untuk menginputkan data customer ataupun data servis, menyebabkan terjadinya perulangan penginputan data dalam penerimaan sevis. Sistem yang manual dalam pemberitahuan progress servis kepada customer yang banyak, sehingga menyulitkan karyawan bagian teknisi, dan juga customer yang menginginkan progress servis yang terbaharui. Penyajian laporan yang tidak rapih, yang menyebabkan tidak terkontrolnya jumlah data servis yang masih dalam pengerjaan, seperti status dapat diambil, dan juga status garansi servis.

Atas dasar identifikasi masalah yang dipaparkan diatas, maka rumusan masalah penelitian ini adalah bagaimana membuat program yang memudahkan proses bisnis perusahaan, dengan memberikan nomor servis supaya tidak terjadi kesalahan dalam pengambilan barang, memberikan satu data yang terintegrasi sehingga tidak terjadi perulangan penginputan data servis, kemudian memberikan data yang terbaharui tentang progress servis untuk customer. Serta menyajikan laporan data servis yang rapih, dan memudahkan perusahaan dalam mengontrol proses pengerjaan maupun status garansi servis yang diberikan kepada customer. Sehingga dapat memberikan pelayanan yang maksimal dan meningkatkan loyalitas pelanggan.

\section{B. TINJAUAN PUSTAKA}

\section{Sistem Informasi}

Jasa merupakan produk tak berwujud, yang biasanya berupa pelayanan yang dibutuhkan oleh user. Sedangkan servis sering disebut dengna istilah perbaikan atau reparasi. Devinisi dari perbaikan itu sendiri adalah usaha perbaikan yang dilakukan terhadap suatu benda atau barang yang rusak akibat pemakaian alat tersebut kedalam kondisi semula. (Damayanti, 2018:43) Didalam usaha perbaikan tersebut tidak menuntuk kesempurnaan atau pengembalian pada kondisi awal secara sempurna, dan hanya mengutamakan alat tersebut dapat berfungsi normal kembali. Dalam perbaikan memungkinkan adanya pergantian sparepart atau komponen, dan untuk beberapa produk yang ada dipasaran tidak tersedia komponen untuk penggantian saat dilakukan perbaikan, oleh karenanya membeli produk baru yang sama adalah pilihan yang terbaik bagi user.

\section{Model Pengembangan RAD}

Model pengembangan perangkat lunak Rapid Application Development (RAD) merupakan metode pengembangan sistem informassi yang dapat mengurangi keterlambatan atau menekankan siklus perkembangan yang sangat pendek (Hari \& Asnawati, 2015:21). Metode ini dirancang untuk melakukan pengembangan dengan periode waktu yang sangat pendek.

\section{ERD}

Entity Relationship Diagram (ERD) adalah model jaringan data yang terstruktur menekankan pada hubungan relasi data. ( Ladjamudin dalam Cahyomo, 2017:78) Salah satu model jaringan dengna menggunakan sususnan data yang tersimpan secara abstrak di dalam sebuah sistem. Erd berfungsi untuk menggambarkan hubungan antara entitasentitas di dalam suatu sistem, erd digunakan untuk melakukan perancangan kemudian dari rancangan tersebut dituangkan kedalam bentuk database.

Ada beberapa jenis hubungan entitas dala erd diantaranya yaitu (Kadir dalam Setiyawati \& Sardiarinto, 2016:36): 
1. One-to-one Disimbolkan (1:1) menyatakan bahwa setiap entitas pada tipe A paling banyak berpasangan dengan satu entitas pada tipe entitas $B$, dan juga sebaliknya.

2. One-to-many Disimbolkan (1:M) menyatakan bahwa setiap entitas pada tipe entitas $A$ dapat berpasangan dengan banyak entitas pada tipe entitas $B$, sedangkan setiap entitas pada $B$ hanya dapat berpasangan dengan satu entitas pada tipe entitas $B$.

3. Many-to-one

Disimbolkan (M:1) menyatakan bahwa setiap entitas pada tipe entitas $A$ paling banyak berpasangan dengan satu entitas pada tipe entitas $B$ dan setiap entitas pada tipe entitas $B$ dapat berpasangan dengan banyak entitas pada tipe entitas $A$.

Many-to-many Disimbolkan (M:N) menyatakan bahwa setiap entitas pada suatu tipe entitas $A$ dapat berpasangan dengan banyak entitas pada tipe entitas B dan juga sebaliknya.

\section{Struktur Navigasi}

Struktur navigasi merupakan struktur alur dari sebuah program. Suatu hal yang perlu dilakukan sebelum membuat program adalam menetukan srtuktur navigasi. (Sugiharto, 2019:184) didalam pembuatan struktur navigasi terdapat 4 macam bentuk dasar yang bisa digunakan. Empat bentuk dasar tersebut adalah sebagai berikut :

1. Struktur Navigasi Linier

Tampilan yang bisa ditampilakan pada struktur navigasi linier adalah satu halaman sebelumnya atau satu halaman setelahnya, tidak bisa dua atau lebih halaman sebelumnya atau setelahnya. Struktur navigasi linier ini hanya memiliki satu rangkaian cerita yang berurutan. Dan menampilkan satu per satu tampilan layar yang berurutan sesuai dengan urutannya

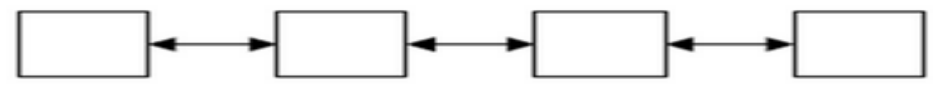

Sumber: Sugiharto (2019)

2. Struktur Navigasi Hirarki

Gambar 1. Struktur navigasi linier

Struktur navigasi hirarki merupakan struktur navigasi yang mengandalakan percabangan untuk menampilkan data berdasarkan kriteria tertentu, struktur navigasi hirarki juga sering disebut struktur bercabang. Tampilan panda menu disebut Master Page (halaman utama atau pertama), halaman ini memiliki halaman cabang yang disebut dengan Slave Page (halaman pendukung). Apabila salah satu dari halaman pendukung dipilih atau aktif, maka tampilan tersebut dinamakan Master Page (halaman utama kedua) dan begitu juga seterusnya.

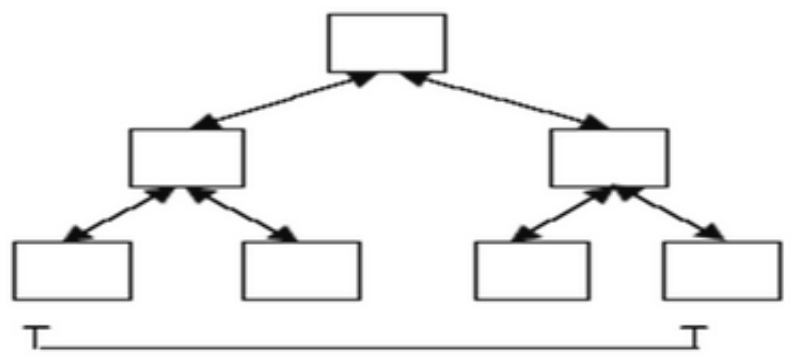

Sumber: Sugiharto (2019)

3. Struktur Navigasi Non - Linier

Gambar 2. Struktur navigasi Hirarki

Pada struktur navigasi non - linier diperkenalkan untuk membuat navigasi bercabang, struktur navigasi ini merupakan pengembangan dari struktur navigasi linier. Percabangan pada struktur navigasi ini berbeda dengan struktur navigasi hirarki. Dikarenakan pada percabangan non linier walaupun terdapat percabangan ,tetapi setiap tampilan memiliki kedudukan yang sama, tidak seperti pada struktur navigasi yang terbagi menjadi Master Page dan Slave Page. 


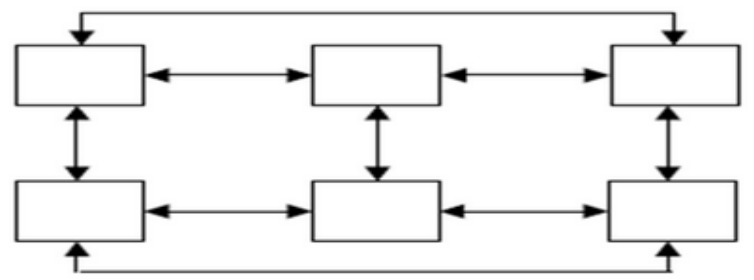

Sumber: Sugiharto (2019)

Gambar 3. Struktur navigasi non-linier

4. Struktur Navigasi Composite (Campuran)

Struktur navigasi composite (campuran) juga sering dikenal dengan struktur navigasi bebas, struktur navigasi campuran merupakan gabungan dari ketiga struktur navigasi yang ada. Struktur navigasi ini dapat digunakan pada pembuatan multimedia karena bisa memberikan keinteraksian yang lebih tinggi.

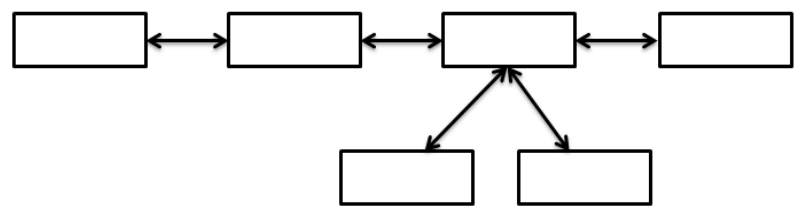

Sumber: Sugiharto (2019)

Gambar 4.Struktur navigasi composit (Campuran)

\section{METODE PENELITIAN}

Model pengembangan perangkat lunak yang digunakan dalam penelitian ini adalah metode Rapid Application Development (RAD). Metode ini merupakan metode pengembangan sistem informassi yang mampu mengurangi keterlambatan atau menekankan siklus perkembangan yang sangat pendek (Hary, dan Asnawati, 2015:21).

Adapun tahapan model Rapid Application Development (RAD) adalah sebagai berikut :

1. Pemodelan Bisnis

Pada penulisan penelitian ini, penulis melakukan penelitian mengenai proses bisnis yang sudah ada, mendapatkan informasi sistem yang berjalan terutama sistem penerimaan jasa servis yang sudah diterapkan saat ini. Pada tahap ini penulis mengumpulkan semua data atau informasi yang didapatkan pada CV. Java Multimedia.

2. Pemodelan Data

Pada penulisan penelitian ini, penulis menganalisa masalah yang ada pada sistem yang sudah berjalan, kemudian memberikan solusi yang tepat untuk permasalahan tersebut dengan merancang kebutuhan dan membangun sistem. Melibatkan pengguna dalam perancangan ini dilakukan secara berulang-ulang untuk mencapai kesepakatan berasama.

3. Proses Pemodelan

Pada penulisan penelitian ini, pada tahap ini dilakukan pemindahan dari tahap analisa, ke desain sampai yang terakhir tahap implementasi penulis membuat desain rancangan berdasarkan permasalahan yang ada dengan mengidentifikasi tujuan sistem dan menentukan syarat informasi yang dihasilkan dari tujuan tersebut, mulai struktur data, arsitektur perangkat lunak, desain antarmuka, dan prosedur pengkodean.

4. Generasi Aplikasi

Pada penulisan penelitian ini, penulis mengimplementasi desain rancangan yang sudah dibuat kedalam bentuk kode program, Penulis menggunakan pemrograman terstruktur dengan bahasa pemrograman php dengan source code editor Dreamweaver CS6 dan database menggunakan Mysql. 
5. Pengujian dan Omset

Pada penelitian ini, untuk memastikan apakah fungsi masukan dan keluaran dari perangkat lunak sudah sesuai dengan kebutuhan yang diharapkan penulis menggunakan pengujian kotak hitam (black box testing). Hal tersebut bertujuan untuk meminimalisir kesalahan dan memastikan keluaran yang dihasilkan sesuai dengan yang diharapkan.

\section{HASIL DAN PEMBAHASAN}

\section{ERD (Entity Relationship Diagram)}

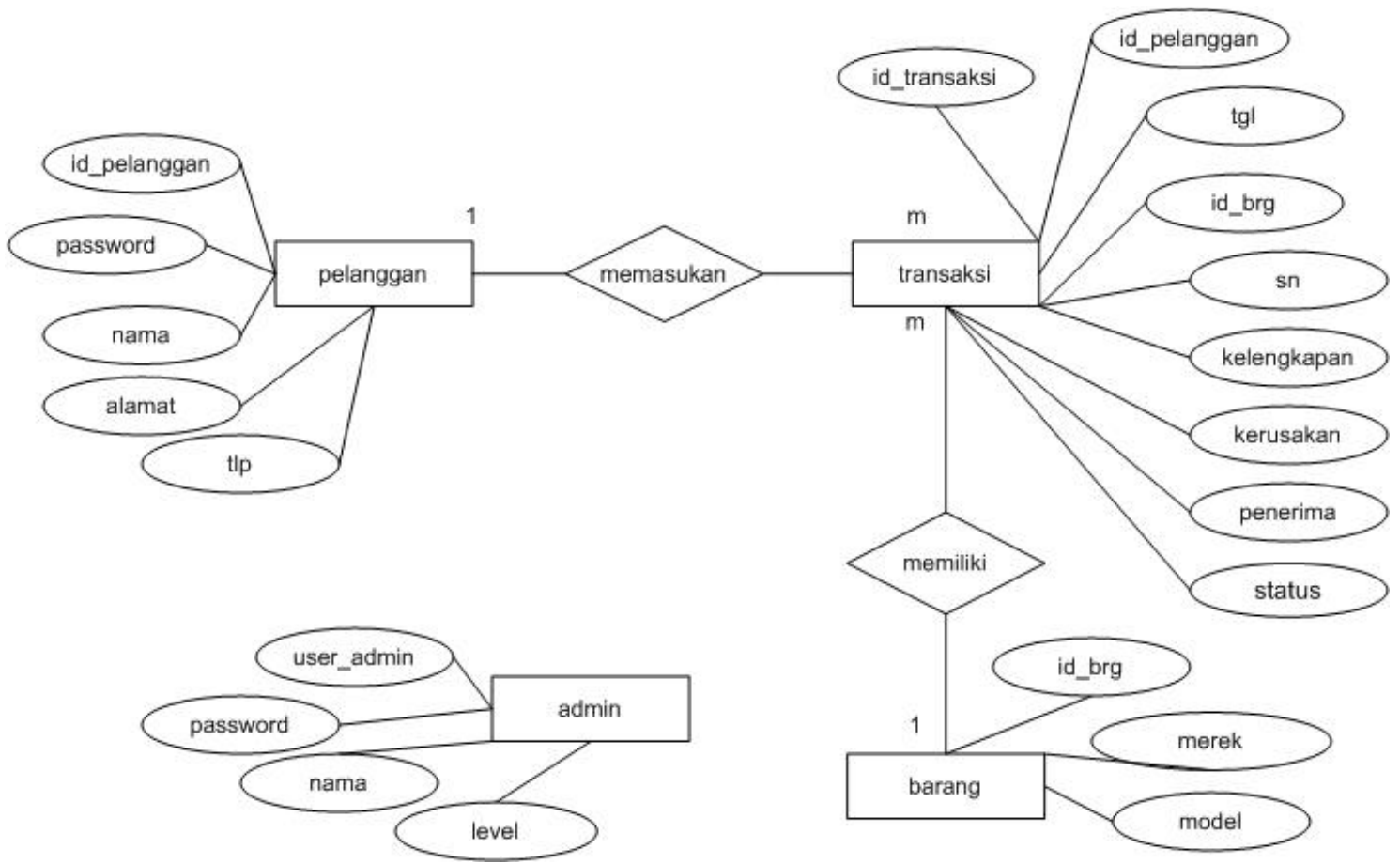

Gambar 5. Entity Relationship Diagram

Sumber: Hasil Olahan Peneliti

\section{LRS (Logical Record Structure)}

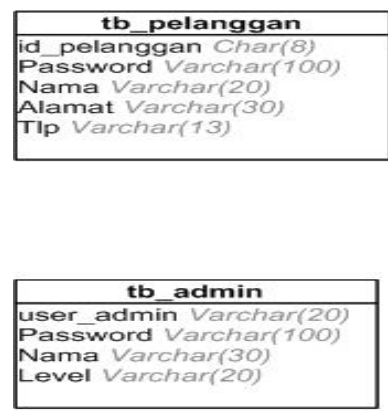

$+m$

tb_transaksi

d pelanggan Varchar(8)

d brg Char ( 8 )

n Varchar(10)

kelengkapan Varchar(30)

Kerusakan Varchar (30)

penerima Varchar(20)

tatus Varchar 30 )

user_admin Varchar(20)

Nama Varchar(30)

tb_baran

Merek Varchar(10)

Model Varchar(10)

Gambar 6. Logical Record Structure

Sumber: Hasil olahan Peneliti

\section{Struktur Navigasi Halaman Index Kasir}

Pada halaman pelanggan menggunakan struktur navigasi hirarki karena pada rangkaian home, data pelanggan, data barang, terima servis, proses servis, bias diambil, garansi dan pogout memiliki percabangan untuk menampilkan data. 


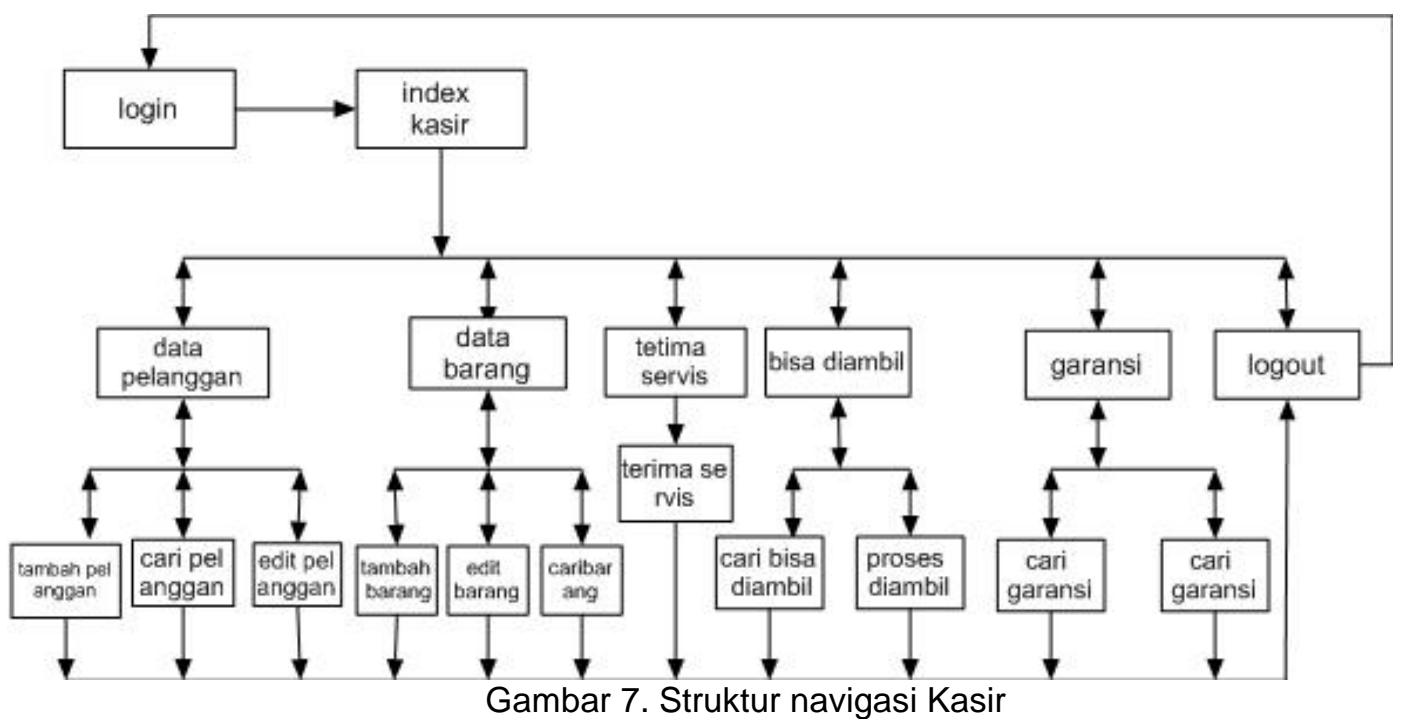

Sumber: hasil olahan peneliti

\subsection{Implementasi}

\section{Halaman Login Admin}

Admin Web dan karyawan (kasir dan teknisi) harus melakukan login terlebih dahulu untuk menggunakan hak aksesnya masing-masing. Jika login berhasil maka menu-menu yang sesuai hak aksesnya akan ditampilkan.

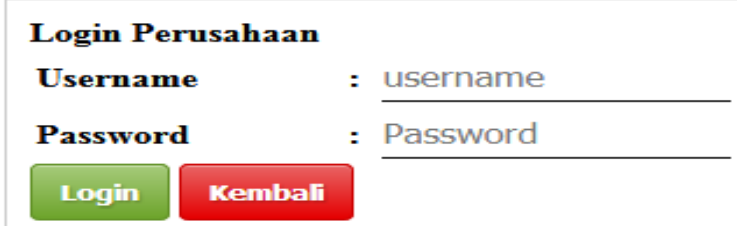

Gambar 8 Login Admin Web dan Karyawan

\section{Halaman Data Pelanggan}

Halaman data pelanggan berisi data-data pelanggan yang bisa diubah, hapus oleh si adminWEB. Selain itu,ada menu untuk menambah data pelanggan. Di sebelah atas ada menu pencarian untuk mencari data berdasarkan idpelanggan dan nama. Di bagian kanan atas terdapat keterangan admin yang sedang login dan juga keterangan waktu sekarang.

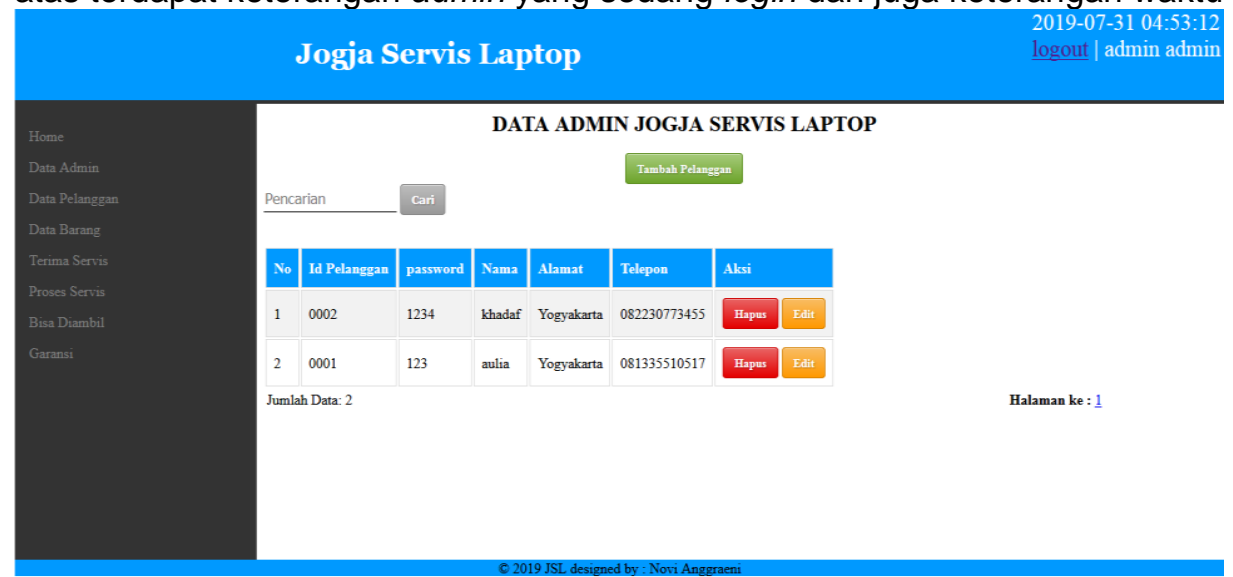

Gambar 9. Halaman Data Pelanggan

ejournal.bsi.ac.id/ejurnal/index.php/ijse

Copyright @ Universitas Bina Sarana

Informatika 
3. Halaman Terima Servis

Halaman Terima Servis berisi teks masukan untuk menambah data servis seperti idpelanggan, idbarang, sn, kelengkapan, kerusakan, penerima, dan status masuk antrian. Kemudian klik tombol simpan untuk menyimpan ke database dan tombol batal untuk menuju ke terima servis tanpa menyimpan.

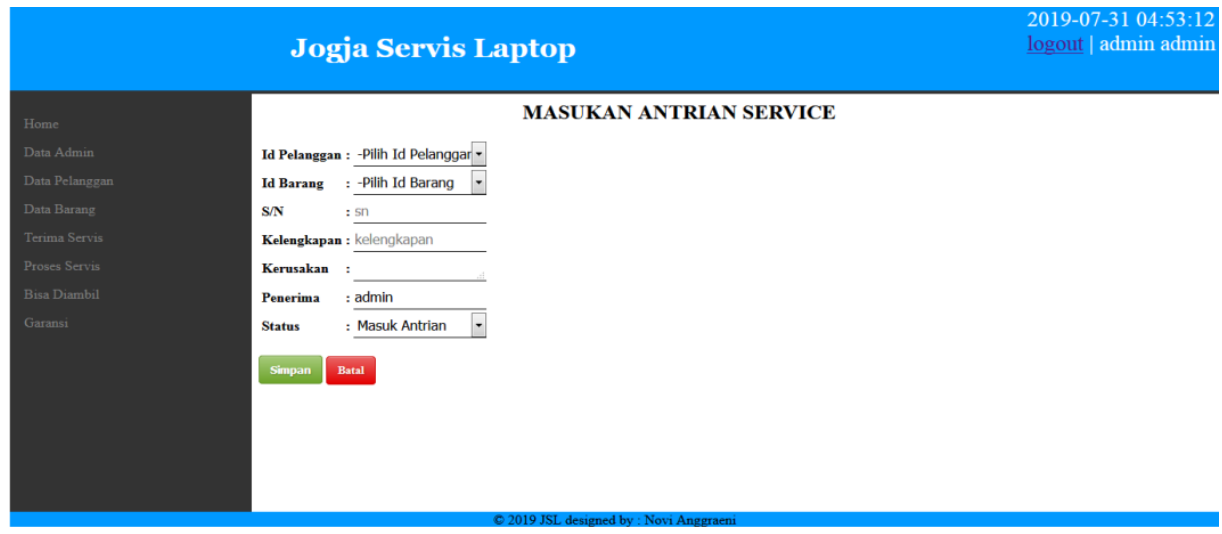

Gambar 10. Halaman Terima Servis

\section{Halaman Proses Servis}

Halaman proses servis berisi data-data servis yang masuk, pada halaman ini admin tidak bias mengubah status atau melakukan proses data servis yang masuk antrian. Di sebelah atas ada menu pencarian untuk mencari data berdasarkan idtransaksi . Di bagian kanan atas terdapat keterangan admin yang sedang login dan juga keterangan waktu sekarang.

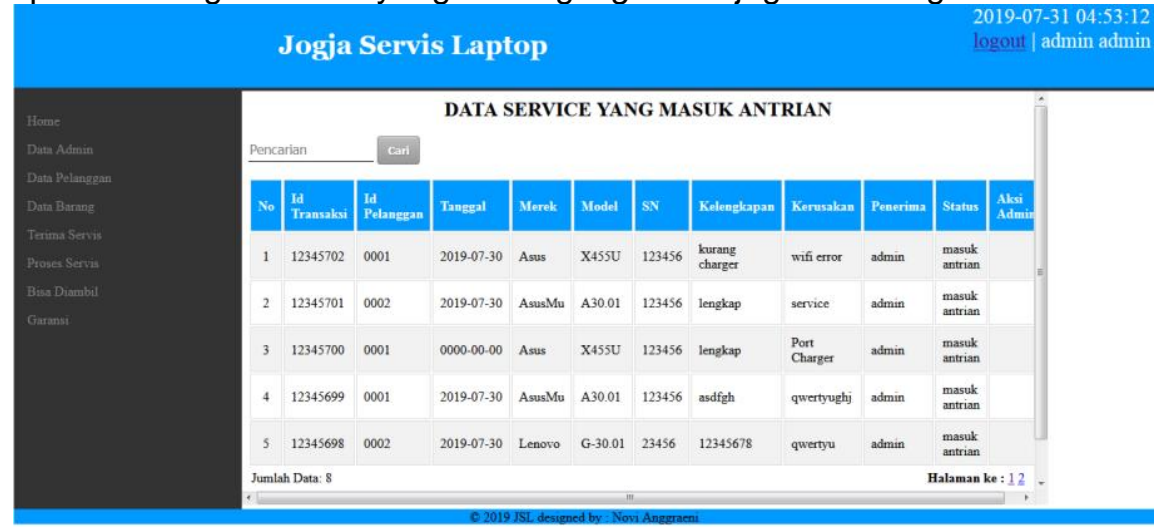

Gambar 11. Halaman Proses Servis

5. Halaman Bisa Diambil

Halaman Bisa diambil berisi data-data servis yang bias diambil, pada halaman ini admin tidak bias mengubah status atau melakukan proses data servis yang masuk daftar sudah bias diambil. Di sebelah atas ada menu pencarian untuk mencari data berdasarkan idtransaksi. Di bagian kanan atas terdapat keterangan admin yang sedang login dan juga keterangan waktu sekarang. 


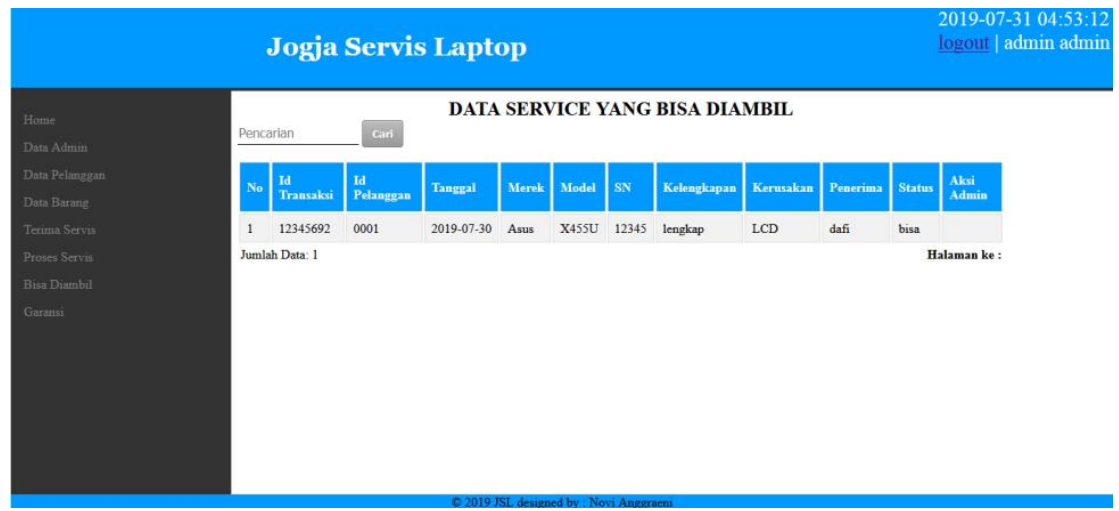

Gambar 12. Halaman Bisa Diambil

6. Halaman Garansi

Halaman Garansi berisi data-data servis yang masih garansi, pada halaman ini admin tidak bias mengubah status atau melakukan proses data servis yang masuk daftar garansi. Di sebelah atas ada menu pencarian untuk mencari data berdasarkan idtransaksi. Di bagian kanan atas terdapat keterangan admin yang sedang login dan juga keterangan waktu sekarang.

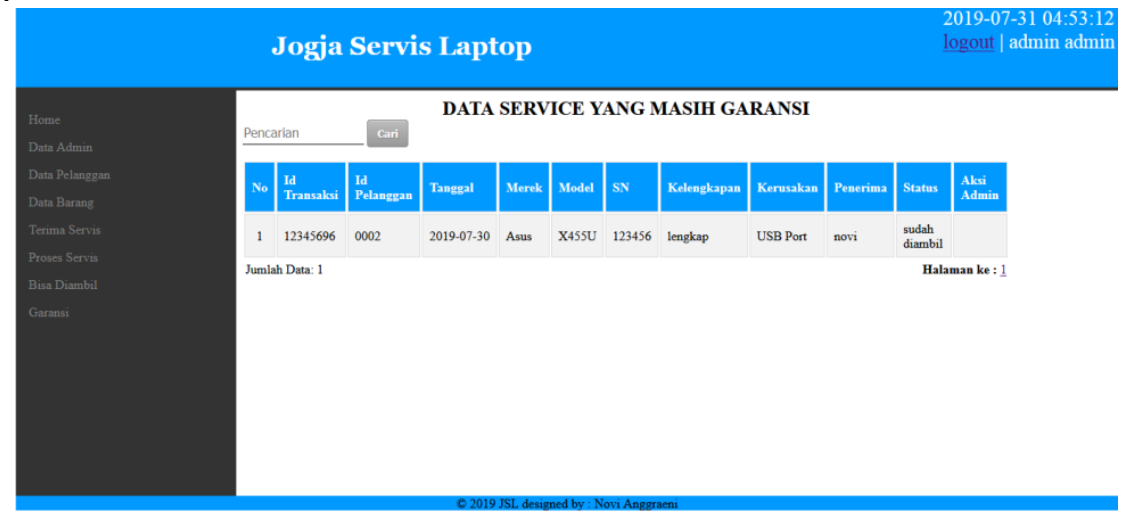

Gambar 13. Halaman Garansi

\section{Halaman Proses Servis Teknisi}

Halaman proses servis berisi data-data servis yang masuk, pada halaman ini teknisi bias mengubah status atau melakukan proses data servis yang masuk antrian. Di sebelah atas ada menu pencarian untuk mencari data berdasarkan idtransaksi. Di bagian kanan atas terdapat keterangan admin yang sedang login dan juga keterangan waktu sekarang.

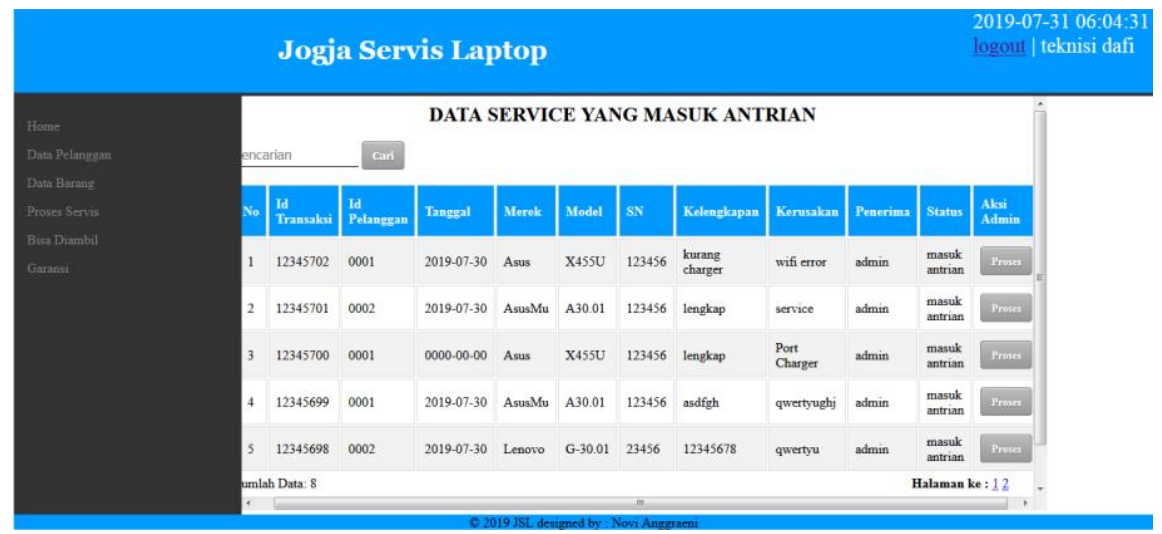

Gambar 14. Halaman Proses Servis Teknisi 


\section{Halaman Bisa Diambil Kasir}

Halaman Bisa diambil kasir berisi data-data servis yang bias diambil, pada halaman ini kasir bias mengubah status atau melakukan proses data servis yang masuk daftar sudah bias diambil. Di sebelah atas ada menu pencarian untuk mencari data berdasarkan idtransaksi . Di bagian kanan atas terdapat keterangan admin yang sedang login dan juga keterangan waktu sekarang.

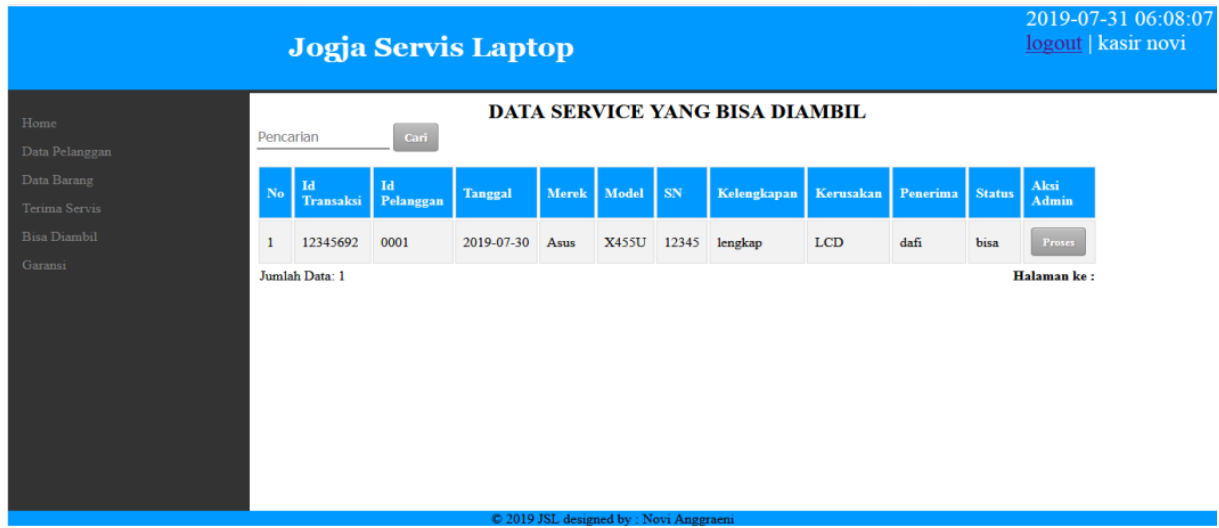

Gambar 15. Halaman Bisa Diambil Kasir

\section{Halaman Garansi Kasir}

Halaman Garansi kasir berisi data-data servis yang masih garansi, pada halaman ini kasir bias mengubah status atau melakukan proses data servis yang masuk daftar garansi. Di sebelah atas ada menu pencarian untuk mencari data berdasarkan idtransaksi. Di bagian kanan atas terdapat keterangan admin yang sedang login dan juga keterangan waktu sekarang.

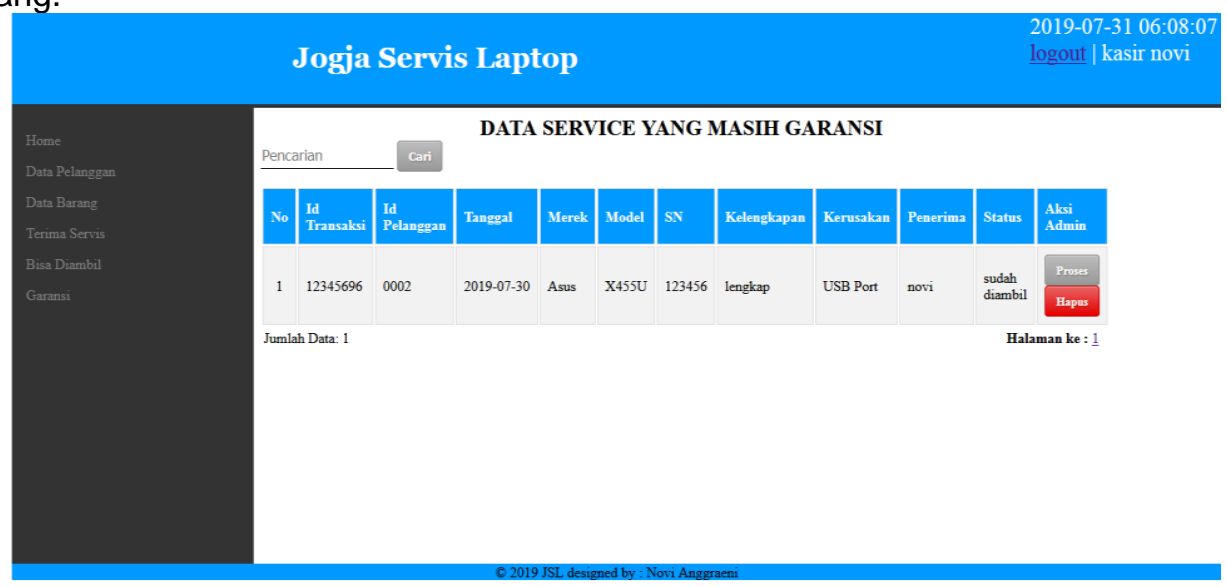

Gambar 16. Halaman Garansi Kasir

10. Halaman Lihat Data Servis

Halaman Lihat data servis berisi data-data servis yang masuk, pada halaman ini pelanggan dapat melihat status transaksi yang dilakukan. Pada halaman ini juga terdapat link whatshapp yang dapat digunakan pelanggan untuk melakukan konfirmasi. Di bagian kanan atas terdapat keterangan pelangggan yang sedang login dan juga keterangan waktu sekarang. 
IJSE - Indonesian Journal on Software Engineering, Vol.6, No. 1, Juni 2020, 33-43

pISSN: 2461-0690 I elSSN: 2714-9935

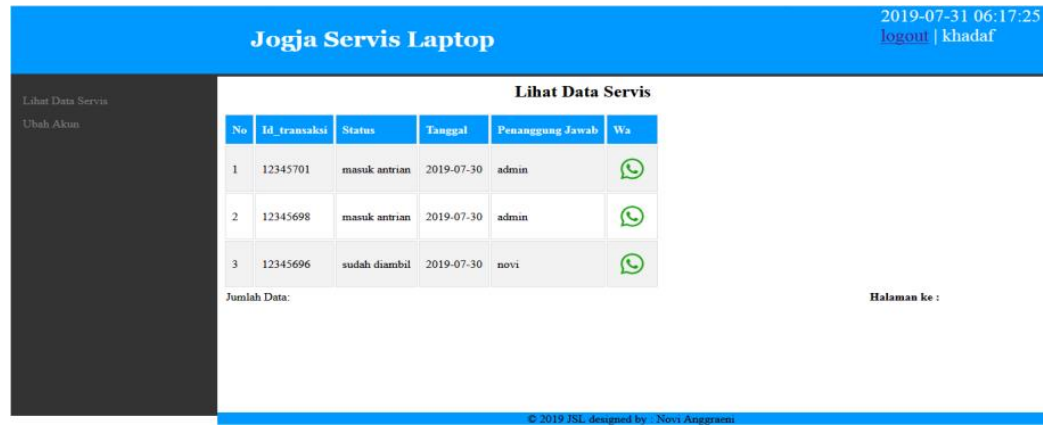

Gambar 17.Halaman Lihat Data Servis

\section{E. KESIMPULAN}

Kesimpulan yang dapat diambil berdasarkan judul dan pembahasan pada bab sebelumnya mengenai perancangan sistem informasi penerimaan jasa servis pada CV. Java Multimedia Yogyakarta yaitu :

1. Website ini dapat dijadikan media informasi perusahaan untuk memberikan pelayanan kepada customer secara cepat, efektif dan lebih maksimal .

2. Website ini dapat meminimalkan masalah mengenai persoalan yang dihadapi perusahaan yaitu tertukarnya barang servis masuk, dengan adanya nomer servis yang memudahkan karyawan dan juga custemer.

3. Apabila website sistem informasi penerimaan jasaservis pada CV. Java Multimedia Yogyakarta ini diterapkan, dapat membantu pelanggan dalam mengecek status atau progress servis.

4. Proses perancangan website sistem informasi penerimaan jasa servis pada CV. Java Multimedia ini diselesaikan dengan metode Rapid Application Development (RAD).

5. Pengujian yang digunakan dalam perancangan website sistem informasi penerimaan jasa servis pada CV. Java Multimedia Yogyakarta menggunakan pngujian black-box-testing.

\section{REFERENSI}

Abdullah, R. (2016). Easy \& Simple Web Programming. Jakarta: PT Elex Media Komputindo.

Abdullah, R. (2018). 7 in 1 Pemrograman Web Tingkat Lanjut. Jakarta: PT Elex Media Komputindo.

Agus Sugiharto. (2019). Rancang Bangun Aplikasi Augmented Reality Katalog Barang Elektronik Berbasis Android Menggunakan Unity 3D. Jurnal Sistem Informasi Universitas Suryadarma, 6(1), 179-188.

Bekti, H. bintu. (2015). Mahir Membuat Website dengan Adobe Dreamweaver CS6, CSS dan Jquery. Yogyakarta: Andi Publisher.

Cahyomo, D. E. (2017). SISTEM INFORMASI PENJUALAN PADA BLAST COMPUTAMA PURWOREJO Damar Eko Cahyono Politeknik Sawunggalih Aji Jl . Wismo Aji No 8 Kutoarjo , Purworejo. Ekonomi Dan Teknik Informatika, 5(2). Retrieved from http://ejournal.polsa.ac.id/index.php/jneti/article/download/79/66

Damayanti, I. A. (2018). Sistem Aplikasi Pembayaran Service Penjualan Sparepart Sepeda Motor Honda Pada VC. Aneka Teknik Binjai, 2(2), 40-46. Retrieved from http://jurnal.kaputama.ac.id/index.php/JTIK/article/view/122/0

Dan, S. E., \& Sardiarinto. (2016). PERANCANGAN SISTEM INFORMASI BERBASIS WEB Studi Kasus: KSU BMT Al-Ikhwan Yogyakarta. Indonesian Journal on Computer and Information Technology, 1(1), 34-41. Retrieved from http://ejournal.bsi.ac.id/jurnal/index.php/ijcit/article/view/417/317

Junianto, E., \& Primaesha, Y. (2015). Perancangan Sistem Tracking Invoice Laboraturium Pada Pt Sucufindo (Persero) Bandung. Informatika, II(2), 442-452. https://doi.org/ISSN 23556579

Mulyani, S. (2016). Sistem Informasi Manajemen Rumah Sakit; Analisis dan Perancangan. Bandung: Abdi Sistematika.

Rachmanto, R. (2017). 9 Langkah Membuat Website Gratis. Jakarta: PT Elex Media 
Komputindo.

Rerung, R. R. (2018). Pemrograman Web Dasar.: Deepublish CV Budi Utama. Yogyakarta

Suparwanto, \& Pradiatiningtyas, D. (2017). E-Learning Sebagai Media Pembelajaran Berbasis

Web Pada SMK N 4 Purworejo, 6(4), 1-8. Retrieved from http://ijns.org/journal/index.php/ijns/article/viewFile/1499/1460

Utami Feri Hari, A. (2015). Rakayasa Perangkat Lunak (1st ed.). Yogyakarta: CV. Budi Utama.

Wasiyanti, S., Talaohu, R., Studi, P., Akuntansi, K., Bandung, A., Studi, P., \& Akuntansi, K. (2016). Sistem Informasi Penjualan Obat Berbasis Web Pada Apotek Kondang Waras Depok, XVIII(2), 49-62. $\quad$ Retrieved from http://ejournal.bsi.ac.id/ejurnal/index.php/paradigma/article/download/1181/980

Wiwin, A., \& Sardiarinto. (2018). Perancangan Website Sistem Informasi Pendaftaran Kerja Studi Kasus: PT. Sukses Mandiri Utama. ljns, 7(1), 1-9.

Wiwin Aprilia, \& S. (2018). Perancangan Website Sistem Informasi Pendaftaran Kerja Studi Kasus: PT. Sukses Mandiri Utama. Indonesian Journal on Networking and Security, 7(1), 9. Retrieved from http://ijns.org/journal/index.php/ijns/article/view/1501/1462 